\title{
Characteristics of haze pollution in Beijing-Tianjin-Hebei region of China
}

\author{
Nan Xiang ${ }^{1, a}$, Feng $X^{2, b^{*}}$ \\ ${ }^{1}$ School of Economics and Management, Beijing University of Technology, Beijing 100124, China; \\ ${ }^{2}$ School of Economics and Management, Beijing University of Chemical Technology, Beijing \\ 100029, China; \\ a xiangnan@bjut.edu.cn, b xufeng@mail.buct.edu.cn \\ *Corresponding author: Feng Xu, xufeng@mail.buct.edu.cn
}

Keywords: Haze pollution; PM 2.5 concentration; air pollutants; Beijing-Tianjin-Hebei region

Abstract. Haze pollution has become one of the most serious environmental problems in China, especially in Beijing-Tianjin-Hebei region. Chinese government has issued a haze control policy in 2013, which aims to alleviate haze pollution through reducing emission of air pollutants. However, there is a doubt whether the haze concentration target can be achieved through implementation of the air pollutants emission reduction plan. This paper focused upon the numerical relationship between haze concentration and air pollutants emission based on data analysis approach in the Beijing-Tianjin-Hebei region. The haze control policy in the Beijing-Tianjin-Hebei region should shift from concentration target to emission control target. Tianjin and Hebei should reduce much more air pollutants emission. Beijing should consider a more reasonable concentration target and emission control plan for joint-regional efforts.

\section{Introduction}

Haze pollution is one of the long-standing and most important environmental problems in China today. In January 2013, for instance, this affected most parts of the north and east of China, covering an area of over $1.3 \mathrm{~m} \mathrm{~km}^{2}$ and an estimated population of 850 million people [1]. The Beijing, Tianjin and Hebei region (or Jing-Jin-Ji region) located in northeast China is the most polluted area. During 2013 and 2014,7 of the 10 cities with the highest annual average PM 2.5 concentration were located in the Hebei Province, with Beijing and Tianjin ranked $13^{\text {th }}$ and $11^{\text {th }}$ respectively in 2013 . Furthermore, the PM 2.5 annual daily average concentrations of Shijiazhuang and Xingtai in Hebei Province reached 155.2 $\mu \mathrm{g} / \mathrm{m}^{3}$ and $148.5 \mu \mathrm{g} / \mathrm{m}^{3}$ respectively in 2013 , almost four times the national air quality standard of 35 $\mu \mathrm{g} / \mathrm{m}^{31}$ to be introduced in 2013 .

Haze is an atmospheric phenomenon where dust, smoke and other dry particles obscure the clarity of the sky; it is usually created by physical and chemical processes involving fine particulate matter interacting with water vapor under certain air flow conditions [2]. Haze pollution occurs when the PM 2.5 concentration level in the atmosphere is high and, as serious haze events have occurred much more frequently in China in recent years.

\section{Significant correlation between PM2.5 and air pollutants emission}

There is currently an increasing amount of research into haze and PM 2.5 pollution and control, including chemical and composition analysis, environment control strategy analysis and health risk analysis. A fundamental research area is the study of the composition of haze pollution and decomposition of the factors affecting haze, which mainly focuses on the physical and chemical characteristics of PM 2.5 in order to understand the essence of haze pollution. Chemical analysis of PM 2.5 is also used to identify emission sources. Research [3] has determined that the total amount of PM 2.5 is the sum of precursor pollutant emissions and secondary particles, with the precursor pollutants including sulfur dioxide $\left(\mathrm{SO}_{2}\right)$, nitrogen oxides ( $\mathrm{NOx}$ ) and direct PM 2.5, and secondary particles 
comprising various substances generated by precursor pollutants. PM 2.5 control is set as $\mathrm{SO}_{2}, \mathrm{NOx}$, volatile organic compounds (VOC) and ammonia. For research in China, PM 2.5 composition analysis also recognizes $\mathrm{PM} 2.5$ as a compound pollution that is connected with $\mathrm{SO}^{2}$ emissions, $\mathrm{NOx}$, smoke and dust [4,5].

Table 1 shows that Beijing-Tianjin-Hebei region has relative high PM2.5 concentration in 2013 and 2014, much higher than WHO standards.

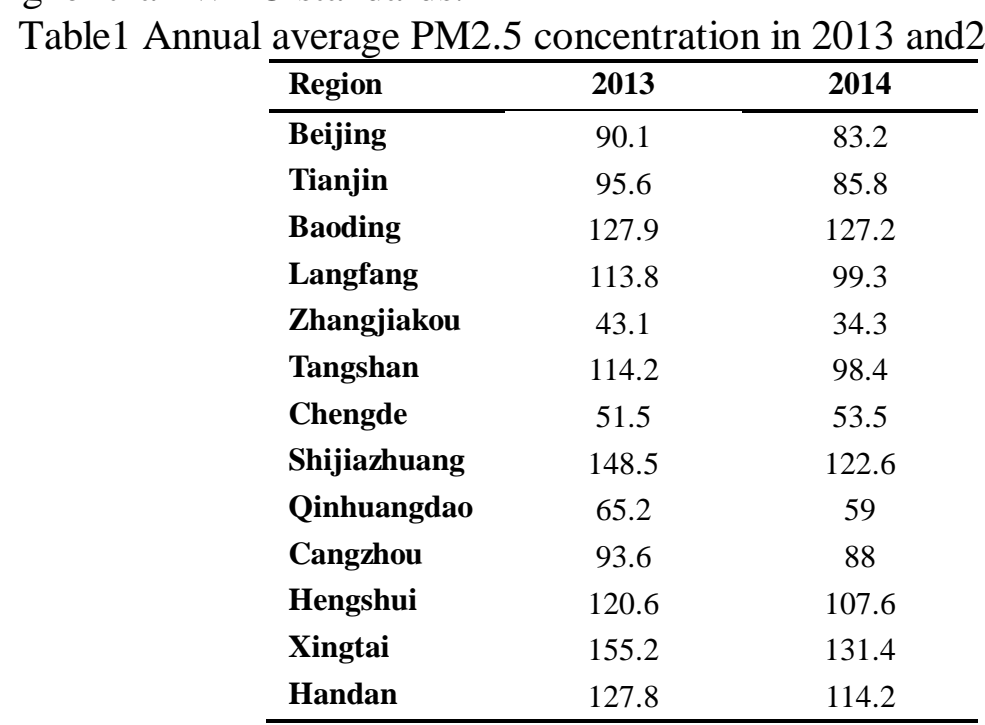

Source: Green Peace organization

From the statistical analysis of PM 2.5 and the three air pollutants (Fig. 1), it is clear that the PM 2.5 concentration has significant positive correlation with $\mathrm{SO}_{2}, \mathrm{NO}_{2}$, and $\mathrm{PM} 10$ concentrations in Beijing-Tianjin-Hebei region.

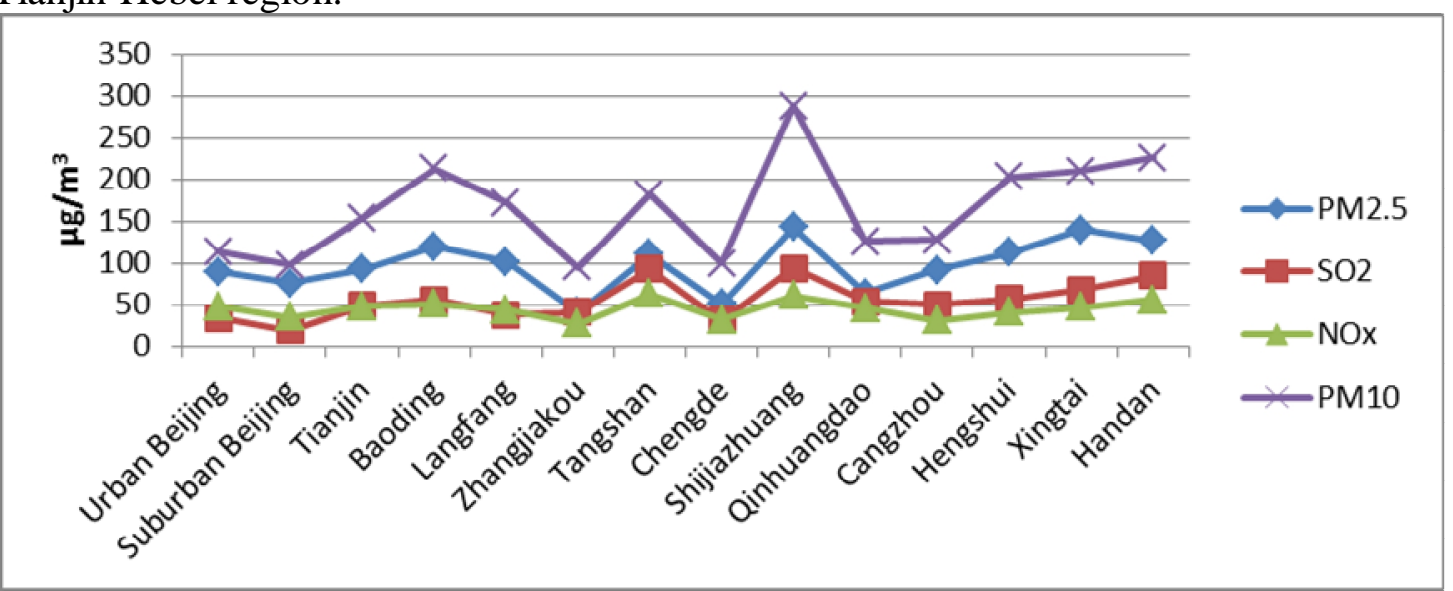

Fig. 1 Annual concentration of PM2.5 and air pollutants in 2013

Source: regional Statistical Yearbook in 2013 and the Environment and Environment Bulletin

\section{Wind as the main force of reducing haze pollution}

According Table 2, PM2.5 concentration has high negative correlation with wind levels. PM 2.5 concentration are declining together with increasing wind speed, for larger air pollutants diffusion ability brought by wind. Also, because of air pollutants emission amount are different in each place, each regions can get acceptable air quality (less than $75 \mu \mathrm{g} / \mathrm{m}^{3}$ ) at various wind level. For instance, Beijing-Tianjin-Hebei region's air quality can be reduced to $65 \mu \mathrm{g} / \mathrm{m}^{3}$ when wind level is in fourth level, which can reduced over $30 \%$ compared with current $90 \mu \mathrm{g} / \mathrm{m}^{3}$. 
Table2 Annual average PM2.5 concentration with different wind levels in 2013

\begin{tabular}{llll}
\hline Wind level & $\begin{array}{l}\text { Annual average } \\
\text { PM2.5 } \\
\text { concentration } \\
\left(\mathbf{u g} / \mathbf{m}^{\mathbf{3}}\right)\end{array}$ & Ratio & PM2.5/PM10 \\
\hline Less than level 2 & 110.61 & $54.24 \%$ & $60.35 \%$ \\
Level 3 & 91.03 & $24.63 \%$ & $55.18 \%$ \\
Level 4 & 64.67 & $15.67 \%$ & $53.87 \%$ \\
Level 5 & 34.07 & $4.54 \%$ & $44.66 \%$ \\
Larger than level 6 & 21.86 & $0.92 \%$ & $44.51 \%$ \\
\hline
\end{tabular}

\section{Regional linkage characteristic is significant}

Another characteristic of haze in the Beijing-Tianjin-Hebei region is the close linkage between each area. Observing the PM 2.5 concentration trends in these three regions, it is noticeable that higher concentrations often occur at the same time. Recalling Wang et al. (2013) analysis of Beijing PM 2.5 sources, in which $19 \%$ of pollutants in the heavy haze events of January 2013 were regional arrivals, it is important to analyze such neighborhood effects here too [6]. Haze and air pollution are also easily transferred between neighboring areas. Therefore, it is unreasonable to control haze pollution only in Beijing area, joint-region efforts on air quality improvement is needed.

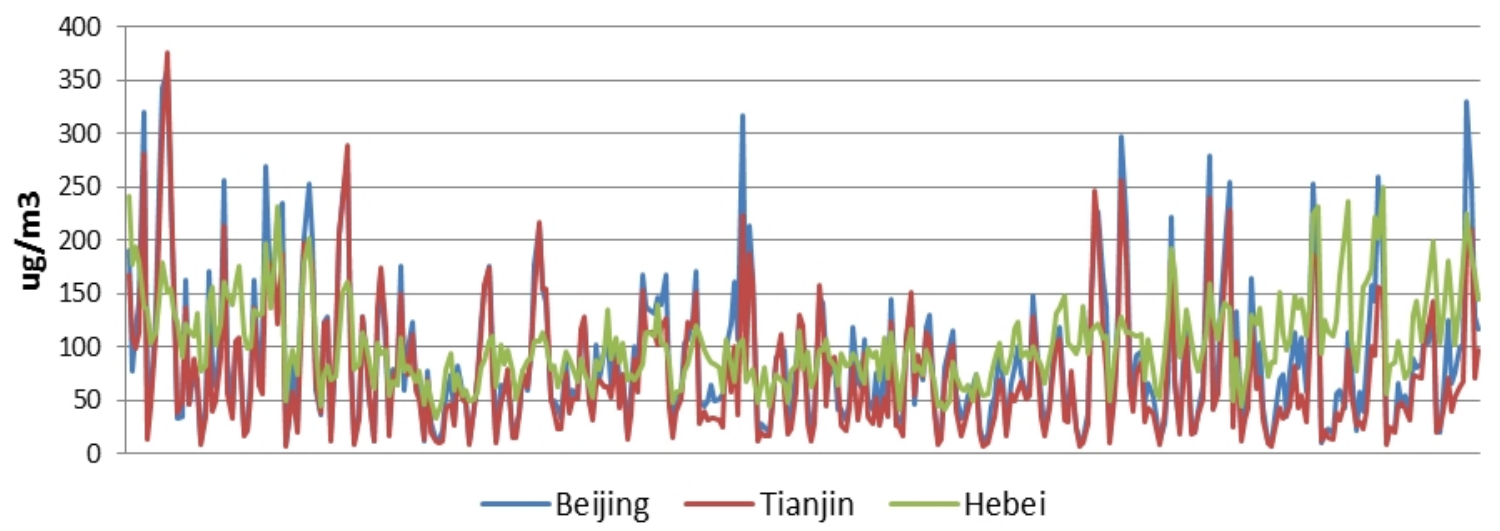

Fig. 2. 2013 regional PM 2.5 concentration trends

A closer examination in Fig.3 indicates a large regional disparity in the Beijing-Tianjin-Hebei area, with haze pollution in south being heavier than the north. Cities in the northern part, like Zhangjiakou, Chengde, and Qinhuangdao, they have relatively good air conditions for PM 2.5 are less than $65 \mu \mathrm{g} / \mathrm{m}^{3}$ in 2013; partially because they emit less air pollutants, and partially thanks to their demographic condition with larger air flow capacity.

In short, the descriptive data analysis indicates that air pollutants and neighborhood effects have a positive impact on PM 2.5 concentration amounts, while wind level has significantly negative effect. Also, emission air pollutants are the fundamental reason for the occurrence of haze and PM 2.5 concentration levels are higher in less windy conditions.

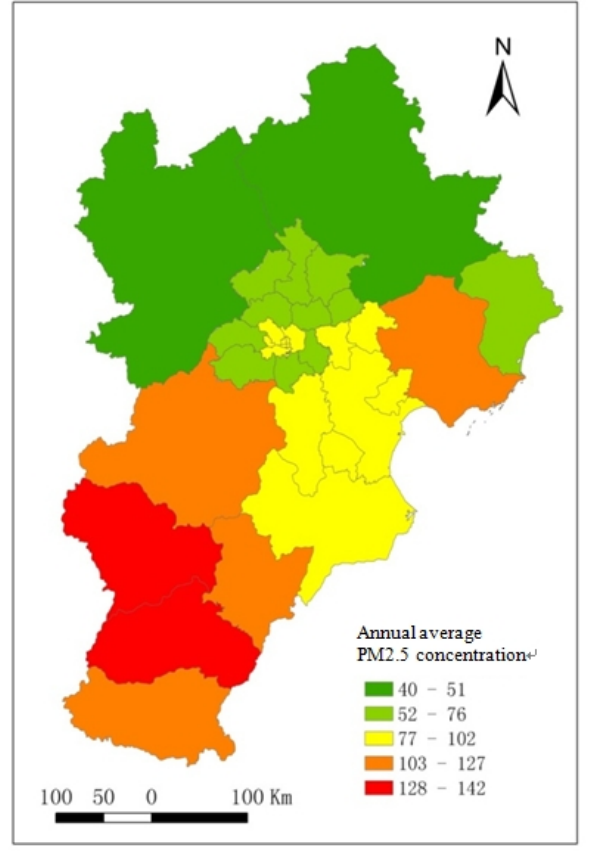

Figure 3. Regional distribution of PM 2.5 annual average concentration Units: $\mu \mathrm{g} / \mathrm{m}^{3}$ 


\section{Conclusions}

Haze pollution has significant damage on human health, Haze pollution in Beijing-Tianjin-Hebei region is serious, in which their annual average concentration is far more than that of national secondary standard, not to mention WHO standards. Therefore it is urgent to control PM 2.5 for China, especially for Beijing-Tianjin-Hebei region.

Through the haze pollution of space distribution, time distribution, the haze of the Beijing-Tianjin-Hebei region has the following prominent features:

(1) Significant correlation between PM2.5 and air pollutants emission. Taking into account the availability of data, haze prevention should be possible through the PM 2.5 precursors of $\mathrm{SO}_{2}, \mathrm{NOx}$, smoke and dust.

(2) Strong negative correlation with wind. Wind is the main force of reducing haze pollution currently. Because the current high pollutant total amount in Beijing-Tianjin-Hebei region, their PM2.5 concentration decline are mainly depends on the weather conditions. Beijing-Tianjin-Hebei region has relatively less rainfall, therefore pollutant diffusion ability relies mainly on the wind.

(3) Regional linkage characteristic is significant. Beijing-Tianjin-Hebei region's daily average concentration change trend also has the remarkable consistency, and higher in southern part, due to the diffusion of pollutant emissions and atmospheric conditions of regional differences. In addition, the haze pollution serious areas are generally with high atmospheric pollutants concentration, demonstrates that overload air pollutant emissions is a major cause of smog pollution.

Haze pollution control need to focus on cutting down on emissions of air pollutants in Beijing-Tianjin-Hebei region, it is the fundamental way to reduce PM2.5 from its source emissions. An approach to this of potential value is the introduction of air pollutant permits to help maximize reduction capacity over a specific time period and minimize human health risks. Furthermore, regional joint-effort on air quality is necessary for this region.

\section{Acknowledgements}

This study is supported by grants from the School of Economics and Management, Beijing University of Technology, School of Economics and Management, Beijing University of Chemical Technology (No. 011000546615006).

\section{References}

[1] Guan D.B., Liu Z.. Haze truth - PM2.5 pollution in Beijing-Tianjin-Hebei region and emission reduction strategy research, China environmental press, Beijing( 2014).

[2] HEI (Health Effects Institute). Outdoor air pollution and health in the developing countries of Asia: A comprehensive review (Special Report 18). Boston, MA. (2010).

[3] Air Division U.S.. Technical Support Document for the Proposed Action on the South Coast 2007 AQMP for PM2.5 and the South Coast Portions of the Revised 2007 State Strategy. California (2010).

[4] Xue, W.B., Wang, J.N., Niu, H., Yang, J.T., Han, B.P., Lei, Y., Chen, H.L., Jiang, C.L. Assessment of air quality improvement effect under the National Total Emission Control Program during the Twelfth National Five-Year Plan in China.Atmospheric Environment, 68, 74-81 (2014).

[5] Wang Y.S., Yao L. et al., Formation of haze pollution in Beijing-Tianjin-Hebei region and their control strategies, Bulletin of Chinese Academy of Sciences, 28(3), p.353-363 (2013).(in Chinese)

[6] Zheng G. J., Duan F. K., Su H.et al,. Exploring the severe winter haze in Beijing: the impact of synoptic weather, regional transport and heterogeneous reactions. Atmos. Chem. Phys., 15, p.2969-2983(2015). 